\title{
Use the calm between the storms
}

\author{
To save lives and livelihoods, natural and social scientists must work with decision-makers and \\ politicians in the time between natural disasters as well as during them.
}

\section{Steve Sparks}

Science has many roles in the forecasting and mitigation of natural hazards. It underlies technological solutions to giving early warning, producing advice for authorities in areas at risk, and designing effective relief strategies. It also provides critical information for policy-makers and the public to help save lives and avoid economic losses. The fulfilment of these roles is in practice complex, and has not been entirely successful - as illustrated by recent events such as the 2004 Asian tsunami, the 2005 Pakistan earthquake, and Hurricane Katrina, which hit the United States in 2005. The time has come to do better as environmental change and population growth will increase vulnerability with the potential for many more disasters.

Most human and financial resources are expended in response to crises rather than in their prevention, and much energy is spent on shifting blame. Political interest in natural hazards is at its highest during and shortly after a disaster - when it is too late. Funding for prevention measures and preparedness is hard to come by when there has not been an arresting earthquake or volcanic eruption for a while, even though prevention is much more cost-effective.

In a crisis, policy-makers are under pressure to be seen to be doing something. Poorly conceived or expensive initiatives are announced and enacted, sometimes with unintended consequences. Then initiatives are quietly forgotten as the crisis declines and political agendas move on.

Take the Asian tsunami. Immediately afterwards, many initiatives were proposed, such as the installation of a technological early-warning system for the Indian Ocean, similar to the existing one in the Pacific. Although this system is now progressing through the auspices of the Intergovernmental Oceanographic Commission, many coastal communities in southern Indonesia remain vulnerable to earthquakes and tsunamis. They are too close to the active faults for the early-warning systems to be effective and complex socioeconomic issues typical of developing-world communities must be addressed to reduce vulnerability.

In the United Kingdom, David King convened the Natural Hazard Working Group of scientists in 2005, and recommended the creation of an international panel to assess global natural hazards. This in turn was proposed by the United Kingdom at the G8 meeting at Gleneagles in 2005. Putting the well-received King proposals into practice has been slow. A scientific policy committee is being established within the framework of the International Strategy for Disaster Reduction (ISDR) of \section{,}
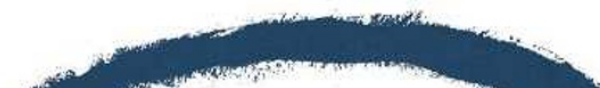

resilience and saved tens of thousands of lives in Bangladesh.

A significant problem for the effective interaction of scientists and policy-makers is the rapid turnover of government officials and politicians. New governments, at least in democracies, alter policies and priorities. In many systems, civil servants and ministers frequently change posts every two or three years and the task of bringing the new people up to speed on the science must begin again.

So how might we develop policies carefully and continuously rather than in response to crises? Structures should be built that allow long-term provision of scientific advice, and analysis of hazards, risks and mitigation strategies in between disasters. The appointment of chief scientific advisers to the major government departments in the United Kingdom is an example of a step in the right direction. Governments need to ensure that the assessment activities and relevant scientific institutions are well funded, that they act on the advice with adequate funding, and that hazards remain on the agenda at all times. There is an urgent need

for cooperation between social and

the United Nations. But this committee does not seem to have the vital function of assessment as proposed by the King group. Once again, as memories of the disasters in 2004 and 2005 fade, the issue slips down government agendas.

Another problem is that successful mitigation is rarely noticed. Only failures and disasters hit the headlines and get political attention. It is much harder to demonstrate that economic losses have been prevented and lives saved than to count deaths and debts.

There are examples of mitigation success stories that deserve highlighting. In 1991, tens of thousands of lives were saved by the timely evacuation of the area around Mount Pinatubo in the Philippines, a few days before one of the largest explosive volcanic eruptions of the twentieth century. Likewise, policies that enforce building codes for earthquake resistance, as exemplified in California, have saved many lives, mostly in the developed world. That said, simple shelters built on artificial high ground on the floodplains of the river Ganges have greatly increased community natural scientists, as it is human activities, infrastructure and behaviour that control vulnerability and turn hazards into risks, resulting in major disasters.

Internationally, there must be more cohesive scientific input to inter-governmental policy-making. The King committee's argument for an international panel on natural hazards remains compelling. Plans for a science policy group within the ISDR are necessary, but not sufficient. There also needs to be more recognition that natural disasters are more than a development issue. Recent disasters such as this year's flooding in Britain and the wildfires in California are a reminder that natural hazards affect developed as well as developing nations.

Mitigation of natural hazards remains inadequately supported through international advisory structures. It seems that the Asian tsunami was not a strong enough wake-up call.

Steve Sparks is professor of geology at the University of Bristol, Bristol BS8 1RJ, UK.

For more essays and information see http://nature.com/ nature/focus/scipol/index.html. 